\title{
OPTIMALISASI RUTE DISTRIBUSI MENGGUNAKAN METODE TRAVELING SALESMAN PROBLEM (TSP) UNTUK MEMINIMASI BIAYA DISTRIBUSI
}

Hilmy Oktorio Zupemungkas; Wiwik Handayani

Progdi Manajemen, FEB UPNV Jawa Timur

E-mail: hilmyzup28@gmail.com

\section{Article Info}

Article History:

Received 29 August - 2021

Accepted 06 Sept - 2021

Available Online 25 Sept -

2021

\footnotetext{
Keyword:

Traveling Salesman

Problem

(TSP),

Distribution, Branch and

Bound
}

\begin{abstract}
UD Global Indonesia or known as GO Sumber Plastik is company engaged in modern retail with a partnership system that sells various plastic products. The retails is spread in various regions of Gresik and Lamongan. Distribution is important activity carried out everyday by the company cause is done to maintain continuity business at GO Sumber Plastik which is currently growing. As the company is growing, it is faced with increasing distribution costs due to various distribution purposes. The company has two fleets with different fuel types (petalite and biodiesel fuel) for two different trips each day. There are two trips as long trips and short trips. However, Sunday is only available for one trip. This research aims to know the optimal distribution route and determining the proper us of vehicle to minimize company distribution costs. Traveling salesman problem with Branch and Bound algorithm is one of the methods to be used to select the most optimal route by WinQSB software. This method will determine the optimal route by visiting a destination point only once. To support the results of the method used, it also aims to know the distribution factors that affect the efficiency of the results obtained. In this research, there are 2 alternatives that can be used by the company. In addition, this research provide advice from external experts from companies who have experience in their fields in overcoming factors that can hinder the company's distribution activities.
\end{abstract}




\section{PENDAHULUAN}

Pada era globalisasi perusahaan dihadapkan dengan kondisi persaingan antar perusahaan baik lokal maupun global memicu perusahaan untuk menggunakan manajemen secara tepat. Perusahaan harus mampu menciptakan kepuasan terhadap konsumen salah satunya yaitu melalui pelayanan yang baik. Hal tersebut dimaksudkan agar perusahaan dapat tetap bersaing di pasar global dengan kondisi lingkungan bisnis yang berubah dengan cepat, dinamis, dan rumit. Distribusi merupakan salah satu faktor penting karena memiliki peranan sentral agar bisnis dapat tetap berjalan yang berkaitan dengan berbagai kegiatan penting seperti perencanaan dan penyediaan dari proses penyimpanan hingga dilakukannya pengiriman sampai ke tangan konsumen (Auliasari et al., 2018).

Dalam pelaksanaannya, perusahaan diharuskan mengeluarkan biaya variabel yang berubah-ubah. Apabila perusahaan tidak merencanakan manajemen pendistribusiannya secara tepat, dapat berakibat membesarnya biaya distribusi yang harus dikeluarkan oleh perusahaan. Dilansir dari www.cnnindonesia.com (2020) Presiden Republik Indonesia mengeluhkan mengenai biaya distribusi yang mahal antar daerah. Hal tersebut mengindikasikan bahwa terdapat dampak dari pemilihan transportasi dan pemilihan rute yang dapat menyebabkan biaya distribusi lebih besar (Moriza, Adiyanto, and Nurdiansyah, 2016).

Pelaksanaan distribusi dilapangan akan dipengaruhi oleh berbagai kondisi. Dalam hal ini, perusahaan akan dihadapkan dengan berbagai kondisi yang dapat mempengaruhi perusahaan untuk menentukan metode penelitian yang tepat agar kondisi tersebut tidak menghambat pendistribusian perusahaan. Menurut Sukma (2019), Pemindahan produk dari perusahaan ke konsumen dipengaruhi oleh berbagai faktor yang terjadi dilapangan. Tanpa perencanaan yang tepat terhadap kondisi - kondisi tersebut maka perusahaan akan dihadapkan dengan permasalahan yang dapat menghambat pendistribusian dan memungkinkan terjadinya peningkatan biaya distribusi.

GO Sumber Plastik dengan nama yang terdaftar secara hukum UD Global Indonesia adalah perusahaan yang bergerak dalam perdagangan plastik berbasis retail modern dan bisnis kemitraan. GO Sumber Plastik kini sedang mengalami perkembangan yang cukup pesat. Kini GO Sumber Plastik memiliki toko retail maupun sub mitra sejumlah 12 toko yang tersebar diberbagai wilayah di Kabupaten Gresik dan Kabupaten Lamongan. Namun, semakin berkembangnya perusahaan menyebabkan biaya distribusi mengalami kenaikan. Dapat dilihat data pada tabel 1 yang diambil pada tanggal 3 Oktober 2020 bahwa terdapat kenaikan yang signifikan pada kuartal ke III 2020. Pada kuartal II 2020 terdapat penurunan karena dampak dari pandemi Covid-19 tepat pada tanggal 28 April 2020 dilaksanakan PSBB oleh pemerintah Kabupaten Gresik dengan ketetapan Peraturan Bupati Gresik nomor 12 tahun 2020 hingga 8 Juni 2020 yang menyebabkan kegiatan bisnis perusahaan terhenti. Pada kuartal I 2020 hingga kuartal III 2020 masih dengan jumlah tujuan distribusi retail-retail yang sama. Dengan adanya kenaikan biaya distribusi yang signifikan pada kuartal III 2020. Sedangkan terdapat pembatasan biaya untuk kegiatan distribusi berdasarkan informasi dari informan kunci yakni sebesar Rp 4.000.000 perbulan atau Rp 12.000.000 perkuartal.

Tabel 1. Biaya Distribusi Oktober 2019 September 2020

\begin{tabular}{|c|c|}
\hline Kuartal & Biaya Distribusi \\
\hline Kuartal IV 2019 & 12.335 .200 \\
\hline Kuartal I 2020 & 12.986 .000 \\
\hline Kuartal II 2020 & 11.867 .000 \\
\hline Kuartal III 2020 & 13.628 .500 \\
\hline
\end{tabular}

Sumber : Akuntan GO Sumber Plastik

Sehingga dalam hal ini, GO Sumber

Plastik memiliki kendala pada penentuan rute teroptimal karena saat ini masih belum memiliki perhitungan yang akurat agar biaya distribusi dapat diminimasi. Penentuan rute dalam pengiriman barang dari satu titik tujuan ke beberapa titik tujuan lainnya merupakan salah satu hal yang menjadi keputusan terpenting karena sangat berpengaruh terhadap biaya transportasi yang dikeluarkan sehingga perlu untuk menentukan rute teroptimal agar biaya transportasi yang dikeluarkan tidak besar (Siraj, 2020).

Terdapat berbagai macam metode yang dapat digunakan untuk menentukan rute 
teroptimal. Traveling Salesman Problem (TSP) merupakan metode yang dapat digunakan untuk menentukan titik perjalanan terefisien dengan perjalanan ke titik lokasi tujuan hanya satu kali setiap titik. Dalam pelaksanaanya, Metode Traveling Salesman Problem (TSP) dapat menyelesaikan permasalahan pendistribusian dengan penemuan penghematan jarak, waktu tempuh, maupun biaya distribusi (D. B. Paillin and Sosebeko, 2017).

Dalam menyelesaikan permasalahan metode TSP terdapat berbagai macam algoritma yang dapat digunakan diantaranya adalah Branch and Bound, Simulated Annealing, Genetic Algorithm, Ant Colony Optimization, Simple Hill Climbing, dan lainlain. algoritma Branch and Bound adalah metode yang tepat untuk menyelesaikan permasalahan tersebut karena hasil yang diperoleh dalam penyelesaian optimal lebih teliti dan lebih baik dari metode lain sebab hasil optimum yang diperoleh biasanya lebih dari satu, sehingga penulis dapat menentukan hasil yang paling optimal dari hasil-hasil yang telah diperoleh (Mursy et al., 2019).

Untuk mendukung hasil penelitian, maka peneliti melakukan wawancara dan observasi berkaitan dengan kondisi di lapangan ketika pendistribusian sedang berjalan. Hal tersebut dilakukan agar

Berdasarkan uraian diatas maka dapat dirumuskan permasalahan yaitu "Bagaimana perencanaan rute distribusi teroptimal yang dapat dilalui UD Global Indonesia dengan menggunakan metode Traveling Salesman Problem (TSP) untuk meminimasi biaya distribusi ?" dan "Apa saja yang menjadi faktor-faktor distribusi di GO Sumber Plastik yang dapat mempengaruhi hasil dari metode traveling salesman problem (TSP)?"

\section{KAJIAN PUSTAKA DAN PENGEMBANGAN HIPOTESIS Manajemen Distribusi}

Proses pemindahan suatu produk atau jasa harus dikembangkan dan dikelola sesuai dengan visi dan misi perusahaan dalam memenuhi kebutuhan dan kenginginan konsumen untuk menghadapi kondisi lingkungan tertentu yang bisa juga dinamakan manajemen distribusi (Suryanto 2016). Sehingga, Manajemen Distribusi dapat didefinisikan sebagai suatu strategi dalam mengembangkan saluran distribusi dengan melakukan planning atau perencanaan, organization atau pengorganisasian, operation atau mengoperasikan, dan controling atau pengawasan untuk mencapai tujuan perusahaan. Dengan adanya manajemen, saluran distribusi yang direncanakan diharapkan dapat menyesuaikan dengan kondisi lingkungan perusahaan dan memberikan penyesuaian untuk mencapai tujuan yang diinginkan perusahaan. Tujuan perusahaan tak lepas dari kebutuhan dan keinginan konsumen agar kepuasan dapat terjaga atau bahkan meningkat karena dalam distribusi ada 2 peran yang saling mempengaruhi yaitu produsen sebagai sisi prinsipal yang memiliki peran untuk memastikan bahwa produk bisa tersebar secara merata dan konsumen yang memiliki peran sebagai bagaimana konsumen dapat menerima produk atau jasa dengan mudah (Suryanto 2016).

Terdapat 2 sistem manajemen distribusi yang beredar menurut Suryanto (2016), yakni :

1. Paradigma lama (old paradigm), yang berarti penentuan target penjualan untuk setiap jalur distribusi lebih berorientasi pada produsen sehingga produsen memiliki kuasa dalam menentukan permintaan dari mitra dan timnya dalam pendistribusian. Kunci keberhasilan distribusi ini adalah SCP (spreading, coverage, dan penetration)

2. Paradigma Baru (new paradigm), yang dimana permintaan penjualan produk atau jasa berdasarkan kebutuhan pelanggan sehingga produsen hanya sebagai sarana untuk pemenuhan permintaan dari sejumlah produk atau jasa yang dibutuhkan pelanggan. Sehingga produsen harus mengatur logistiknya sedemikian rupa agar hal tersebut bisa dilaksanakan. Keberhasilan logistik tersebut adalah Ditotef (delivery in full on time error free).

\section{Distribusi}

Menurut Effendi et al. (2016), Distribusi merupakan salah satu faktor penting bagi suatu perusahaan dalam melakukan pengiriman produk atau jasa secara tepat kepada pelanggan. Dalam hal ini, ketepatan tersebut berkaitan dengan dasar penjadwalan dan pemilihan rute teroptimal hingga sampai ke tangan pelanggan sesuai dengan batas waktu dan permintaan 
pelanggan. Menurut Auliasari et al. (2018), Distribusi sendiri merupakan kegiatan yang berhubungan dengan perencanaan dan penyediaan informasi terkait dengan proses penyimpanan hingga pengiriman suatu barang. Dalam prosesnya terdapat jenjang yaitu mulai dari lokasi penyimpanan pusat produksi, pusat distributor, tempat grosir, dan eceran. Untuk memiliki manajemen distribusi yang baik diperlukan perencanaan, yang membutuhkan data permintaan tiap titik lokasi konsumen yang didukung data - data lainnya seperti jarak, waktu tempuh, biaya distribusi, dan lain sebagainya. Adapun tujuan dari distribusi adalah untuk menyalurkan produk - produk yang dihasilkan oleh perusahaan ke berbagai daerah yang berbeda - beda sehingga sampai ke sasaran segmen perusahaan tersebut (Fitri, Huda, and Tasri 2016).

Adapun Beberapa fungsi dasar distribusi yang dapat disimpulkan dari buku Supply Chain manajemen I Nyoman Pujawan \& Er (2017), yakni :

1. Pemilihan moda transportasi

Dalam membuat keputusan pemilihan jenis transportasi yang akan digunakan untuk mendistribusikan produknya, perlu memperhatikan kelayakan, keunggulan, dan kekurangan setiap jenis transportasi. Terdapat berbagai macam jenis transportasi yang dapat digunakan perusahaan untuk menjalankan pendistribusiannya. Pada tabel 2.1 dapat diketahui beberapa hal yang menjadi pertimbangan tiap perusahaan dalam memilih moda transportasinya. Selain itu masih terdapat alternatif transportasi yang bisa dipergunakan oleh perusahaan seperti sepeda motor, sepeda pancal, dan masih banyak lagi.

2. Melakukan segmentasi dan menentukan target service level

Perusahaan perlu memahami perbedaan karakteristik dan kontribusi setiap pelanggan dengan melihat area distribusi agar pengalokasian persediaan maupun kecepatan pelayanan dapat dioptimalkan. Beragamnya pendistribusian yang harus dijalankan disebabkan banyaknya pelanggan mengharuskan perusahaan untuk menentukan service level seperti service level kelas 1 yang di memberikan revenue lebih tinggi dibanding service level kelas 2 atau seterusnya sehingga perusahaan dapat menggolongkan karakteristik dan kontribusi pelanggan sehingga revenue yang didapat perusahaan lebih maksimal namun juga pelayanan yang diberikan lebih optimal

3. Melaksanakan konsolidasi informasi dan pengiriman

Mengumpulkan informasi terkait permintaan berbagai lokasi pendistribusian merupakan tugas yang dimaksud agar pengiriman dapat dijalankan secara efisien dengan mempertimbangkan kuantitas muat barang kendaraan dan lokasi yang dapat dikunjungi dalam satu waktu yang sama.

4. Merencanakan penjadwalan dan penentuan rute pengiriman

Tugas pendistribusian adalah menentukan waktu pelaksanaan pengiriman dan menentukan rute yang akan dilalui untuk memenuhi permintaan dari sejumlah pelanggan.

5. Memberikan pelayanan nilai tambah

6. Menangani pengembalian (return)

7. Jaringan distribusi

Dalam penelitian yang dilakukan oleh Sukma (2019) terdapat beberapa faktor faktor yang mempengaruhi Distribusi, yaitu :

1) Jumlah produk

Kuantitas produk yang dihasilkan akan berpengaruh pada proses pendistribusian. Semakin banyak produknya maka akan semakin lama waktu yang diperlukan untuk mendistribusikan. Begitupula sebaliknya.

2) Sifat produk

Dalam produk ada sifat produk yang tahan lama dan cepat rusak. Produk yang cepat rusak seperti hasil pertanian maka memerlukan waktu penyaluran yang cepat.

3) Sarana prasarana dan komunikasi

Ketersediaan sarana prasarana khususnya transportasi yang baik akan meningkatkan aktivitas pendistribusian. Termasuk juga bila ada komunikasi yang berkesinambungan.

4) Luas daerah

Persebaran target konsumen menyebabkan proses pendistribusian yang panjang. Sebaliknya, apabila konsumen berada di lokasi yang berdekatan maka waktu transfer akan relatif singkat

5) Faktor biaya 
Distribusi merupakan aktivitas yang memerlukan biaya besar. Biaya tersebut meliputi sarana angkutan, biaya perjalanan dan pajak angkutan. Apabila tersedia biaya yang mencukupi maka proses akan semakin berjalan lancar.

6) Faktor pasar Apabila pasar menunjukkan trend positif terhadap produk maka meningkatkan aktivitas pendistribusian.

7) Pola pembelian

Laporan pembelian dan feedback dari distributor akan menjadi pertimbangan keberlanjutan proses pendistribusian.

8) Faktor produsen atau perusahaan Produsen harus memperhatikan permintaan konsumen akan suatu produk. Sehingga, mengetahui benar sifat dari produk tersebut.

Adapun faktor-faktor menurut Alfiani (2015) adalah sebagai berikut :

1. Keterlambatan Armada

Keterlambatan ini disebabkan karena faktor kendaraan atau armada yang digunakan pasti memiliki daya kecepatan yang terbatas. Sehingga, pemilihan kendaraan atau armada yang tepat dalam suatu pendistribusian perlu diperhatikan agar pengiriman dapat berjalan dengan lancar

2. Kemacetan

Kemacetan merupakan faktor umum yang terjadi pada setiap pengiriman, terlebih di daerah yang padat penduduk dan waktu aktivitas.

3. Kecelakaan

Terjadi kecelakaan menyebabkan pengiriman menjadi tertunda. Baik itu ketika barang yang aman maupun rusak karena kecelakaan, namun hal ini menjadikan keterlambatan akan memakan waktu lebih lama

4. Cuaca

Cuaca atau gejala alam merupakan faktor yang tidak bisa diprediksi oleh manusia sehingga terjadinya keterlambatan ini sewaktu - waktu bisa saja terjadi. Seperti ketika terjadi kebakaran hutan yang membuat lingkungan menjadi kabut karena tebalnya asap menyebabkan terganggunya pengiriman melalui udara dan melambatnya kecepatan kendaraan atau armada darat karena terganggunya pandangan di jalan raya. Selain itu, hujan deras yang berakibat banjir menyebabkan keterlambatan pengiriman bisa terjadi.

5. Keterlambatan karena permasalahan darat lainnya

Faktor - faktor permasalahan darat seperti infrastruktur jalan raya membuat perjalanan pengiriman tidak berjalan normal. Adapun kondisi geografi seperti di area perbukitan dan pegunungan dapat menggangu pendistribusian.

6. Budaya

Faktor budaya ini dapat berupa hari raya keagamaan, hari libur panjang, serta tradisi disuatu daerah dapat menjadi salah satu penyebab terjadinya keterlambatan. Tingginya permintaan pada hari - hari tertentu menyebabkan jadwal pengiriman menjadi lebih padat dikarenakan over load muatan dalam artian muatan di hold pada pengiriman berikutnya.

\section{Traveling Salesman Problem (TSP)}

Traveling Salesman Problem (TSP) merupakan metode yang digunakan untuk menentukan titik perjalanan terefisien dengan perjalanan ke titik lokasi tujuan hanya satu kali setiap titik (D. B. Paillin and Sosebeko 2017). Traveling Salesman Problem dikenal sebagai suatu permasalahan optimasi yang bersifat klasik dan Non Deterministic Polynimial-time Complete (NPC), dimana tidak ada penyelesaian yang paling optimal selain mencoba seluruh kemungkinan penyelesain yang ada. Penyelesaian tersebut melibatkan seorang traveling salesman sebagai pihak yang menjalankan distribusi dari titik awal keberangkatan menuju setiap titik tujuan hingga sampai titik awal sebagai akhir dari sempurnanya perjalanan tersebut (Al Akbar and Sumiati 2013). Secara umum, tujuan metode Traveling Salesman Problem digunakan untuk menperoleh jarak tur perjalanan terpendek atau terdekat sehingga dapat memberikan impact bagi biaya distribusi yang dikeluarkan oleh perusahaan. Metode Traveling Salesman Problem (TSP) dapat menyelesaikan permasalahan pendistribusian dengan penemuan penghematan jarak, waktu tempuh, \& total waktu tempuh..

Adapun macam - macam algoritma yang dapat digunakan untuk menyelesaikan metode tersebut adalah sebagai berikut :

\section{Branch and Bound}

2. Nearest Neighbour 
3. Simulated Annealing

4. Algoritma Heuristic

Penerapan metode Traveling

Salesman Problem yaitu Setiap lokasi yang dikunjungi dan lokasi awal (berangkat dan finish) dilambangkan menjadi sebuah node (V) dalam sebuah graph. Dari kumpulan atau himpunan node tersebut, akan ditarik garis lurus yang menghubungkan setiap nodes tersebut yang bisa dilambangkan edge (E) dalam graph. Sehingga dapat diformulasikan sebagai berikut : Jarak perjalanan dari titik i menuju titik $\mathrm{j}$ disebut $C_{i j}$ lalu variabel keputusan $X_{i j}$ yang merepresentasikan ada tidaknya rute perjalanan dari titik i menuju titik j (D. B. Paillin and Sosebeko 2017).

$$
X_{i j}
$$

$\{1$ apabila terdapat perjalanan dari i ke j

$\{0$ apabila tidak ada perjalanan dari i ke $\mathrm{j}$

Apabila $\mathrm{Z}$ merupakan fungsi dari tujuan Traveling Salesman Problem, fungsi tersebut dapat dirumuskan sebagai berikut :

$\mathrm{Z}={ }_{\text {Den }} \sum_{i=1}^{n} \sum_{j=1}^{n} C_{i j} X_{i j}$
sebagai beril ${ }^{2}$ batasan kendala

$$
\begin{array}{ll}
\sum_{n=1}^{n} X_{i j}=1 & (i=1,2,3, \ldots . . N) \\
\sum_{j=1}^{n} X_{i j}=0 \text { atau 1 } & (i=1,2,3, \ldots . . N)
\end{array}
$$

עari batasan - batasan diatas baik pertama maupun kedua untuk memastikan rute pejalanan yang dipilih untuk mendatangi setiap titik yang akan dikunjungi hanya 1 kali dan meninggalkan titik tersebut juga hanya 1 kali (Daniel B Paillin and Tupan 2018).

\section{Algoritma Branch and Bound}

Algoritma Branch and Bound merupakan metode yang digunakan untuk menentukan penyelesaian optimasi agar mendapatkan hasil teroptimal. Algoritma Branch and Bound memiliki kelebihan dapat memberikan hasil solusi yang optimal dibandingkan dengan algoritma lain dan memiliki tingkat kesalahan yang sedikit, namun branch and bound juga memiliki kekurangan yaitu, dalam pengerjaannya membutuhkan waktu yang tergolong lama, tingkat kesulitan dalam pengerjaannya yang tinggi dan memiliki kompleksitas algoritma (n-1)! Yang dimana $\mathrm{n}$ adalah jumlah kota atau konsumen atau lokasi tujuan (,).

Algoritma ini terdapat 2 langkah yang menjadi alat untuk menyelesaikan suatu permasalahan Traveling salesman problem yakni Branching dan Bounding. Branching merupakan proses untuk memperkirakan semua kemungkinan yang mungkin menuju hasil solusi dengan membuat perkiraan tersebut menjadi cabang atau sub - sub tree. Untuk Bounding merupakan pembatas ketika sedang melakukan Branching dengan cara menentukan nilai batas atas dan batas bawah (Paillin \& Tupan, 2018). Metode ini menggunakan pohon pencarian (search tree), setiap simpul di pohon merupakan representasi dari adanya kemungkinan solusi. Algoritma ini dilakukan dimulai dengan pengisian sebuah nilai ke akar dari pohon pencarian tersebut yang kemudian dilakukan pencabangan dengan memasang sebuah pending node ke pending node lainnya yang levelnya lebih rendah. Apabila terdapat simpul yang tidak mungkin bagi persoalan yang sedang dihadapi maka simpul tersebut memiliki nilai tak terbatas (infinity). Algoritma berhenti ketika sudah tidak mungkin lagi membuat simpul lagi dengan hasil yang lebih rendah dengan kata lain hasil terakhir tersebut adalah simpul yang paling rendah. Sehingga, algoritma Branch and Bound telah menyelesaikan permasalah Traveling Salesman Problem (Al Akbar and Sumiati 2013).

\section{METODE PENELITIAN}

Dalam melaksanakan penelitian ini, pendekatan yang digunakan adalah kuantitatif deskriptif untuk menjawab rumusan masalah pertama dan kualitatif untuk menjawab rumusan permasalahan kedua. Data akan dikumpulkan secara deskriptif kuantitatif yang akan digunakan sebagai gambaran dengan keadaan yang sebenarnya sekaligus untuk mengetahui hasil dari metode yang digunakan. Sedangkan data kualitatif akan digunakan untuk memperkuat dan melengkapi dari data deskriptif kuantitatif.

Jenis Data yang digunakan dalam penelitian ini adalah data primer dan data sekunder. Data Primer diperoleh secara langsung dari obyek penelitian melalui proses pengamatan dilapangan, hasil pengukuran, dan wawancara terhadap pihak-pihak yang terkait dengan permasalahan yang akan diselesaikan. Dalam hal ini, data yang dibutuhkan adalah pemilihan rute distribusi UD Global Indonesia dan Informasi faktorfaktor yang mempengaruhi distribusi. Data sekunder merupakan sumber data penelitian 
yang diperoleh dengan melakukan pengumpulan data yang ada di perusahaan (Dokumen perusahaan). Adapun data yang di peroleh dari perusahaan adalah berupa data profil perusahaan, data armada atau moda transportasi yang digunakan, data lokasi retail, data waktu operasi pendistribusian, dan data biaya bahan bakar.

Pada penelitian ini, terdapat informan yang akan memberikan informasi tambahan dari pihak eksternal perusahaan untuk memberikan sudut pandang yang bertindak sebagai ahli pakar pendistribusian yang disebut informan tambahan. Berikut informan dalam penelitian ini :

1. Informan Kunci

Pihak yang akan menjadi informan kunci adalah yang mengetahui dan memiliki berbagai informasi pokok yang diperlukan dalam penelitian ini. Dalam hal ini yang menjadi informan kunci adalah Kepala Cabang Usman Sadar yang dimana beliau sekaligus menjadi Kepala Gudang pada UD Global Indonesia.

2. Informan Utama

Informan utama merupakan pihak yang terlibat secara langsung dengan apapun yang berkaitan dengan penilitian ini. Dalam hal ini, berkaitan langsung dengan proses distribusi pada UD Global Indonesia. Pihak yang dijadikan Informan utama pada penilitian ini adalah Pengirim atau kurir GO Sumber Plastik.

3. Informan Tambahan

Pihak yang dapat memberikan informasi meskipun tidak berkecimpung secara langsung pada proses yang berkaitan dengan pendistribusian akan menjadi informan tambahan pada penelitian ini. Dalam hal ini, Kepala Cabang Surabaya PT Pan-Indo Superintendence yang akan menjadi Informan tambahan untuk memberikan informasi dari sudut pandang dari ahli dibidang pendistribusian.

Metode yang digunakan untuk mengumpulkan data didalam penelitian ini yakni dengan penelitian lapangan (field research) dan studi kepustakaan (library research). Penelitian lapangan dilakukan dengan cara pengamatan langsung terkait permasalahan didalam penelitian seperti observasi, wawancara dengan para informan dan dokumentasi. Adapun data yang diperlukan yaitu data pemilihan rute reguler atau awal perusahaan, data transportasi yang digunakan, data lokasi retail, data jadwal atau waktu operasional pendistribusian, data biaya bahan bakar perusahaan, dan faktor distribusi perusahaan yang dapat mempengaruhi biaya distribusi. Pada studi kepustakaan, dilakukan dengan membaca dan mempelajari literatur atau sumber yang berkaitan dengan permasalahan didalam penelitian. Dalam hal ini yakni terkait metode traveling salesman problem algoritma branch and bound.

Dalam menyelesaikan permasalahan menggunakan metode traveling salesman problem algoritma branch and bound, Berikut merupakan langkah - langkah yang akan dilakukan dalam penelitian ini : 
Gambar 1. Teknik Analisis

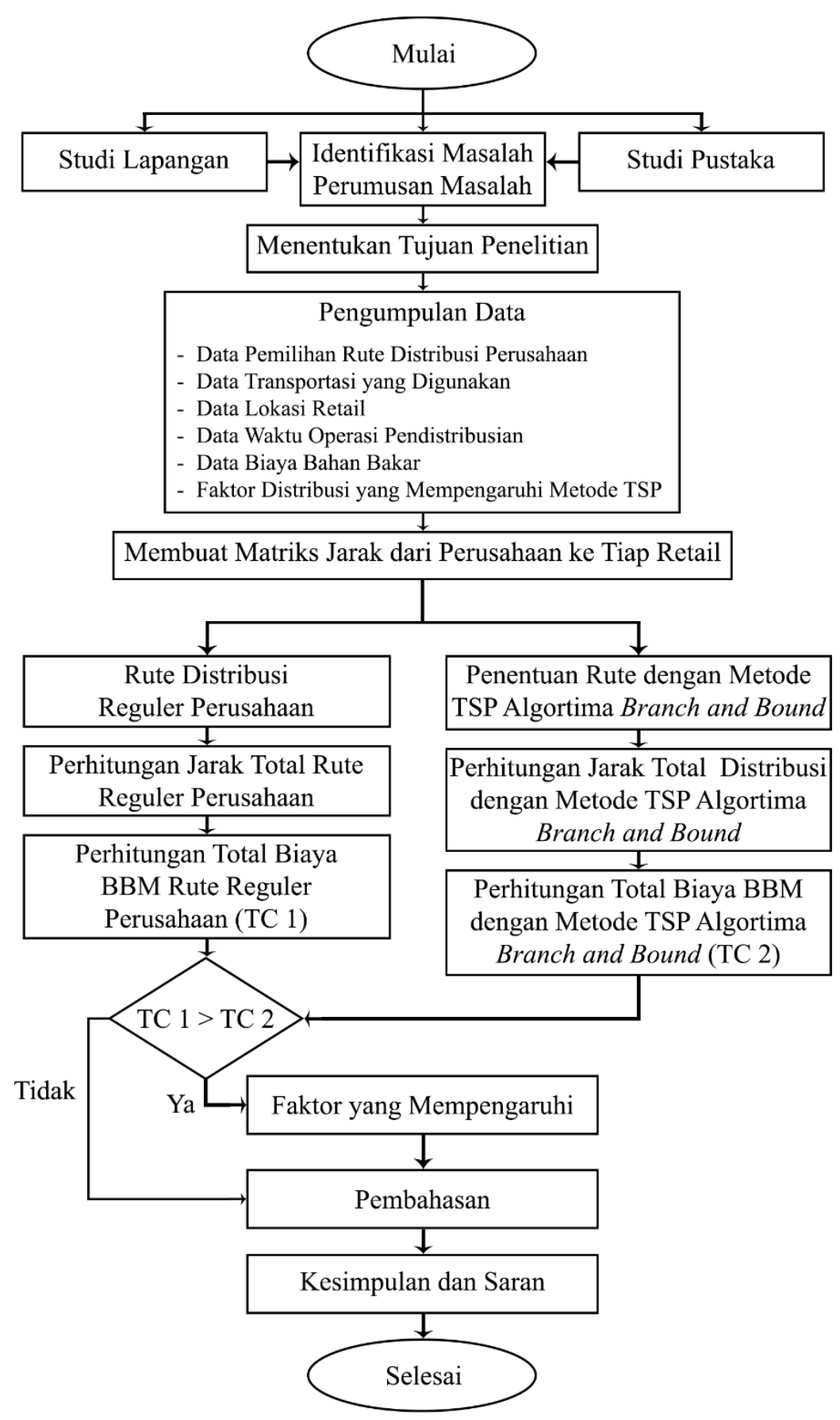


4. HASIL DAN PEMBAHASAN Pengumpulan Data GO Sumber Plastik

Berikut Tabel 2 merupakan data lokasi retail - retail GO Sumber Plastik yang tersebar di berbagai daerah :

Tabel 2. Data Lokasi Cabang Retail GO Sumber Plastik

\begin{tabular}{|c|c|c|}
\hline Kode & $\begin{array}{l}\text { Cabang } \\
\text { Retail }\end{array}$ & Alamat \\
\hline A & $\begin{array}{l}\text { Usman Sadar } \\
\text { (Gudang) }\end{array}$ & $\begin{array}{l}\text { Jl. Usman Sadar no. } \\
\text { 36, Kec. Gresik }\end{array}$ \\
\hline B & GKB & $\begin{array}{l}\text { Jl. Kalimantan GKB } \\
\text { no. } 186, \text { Kec. } \\
\text { Manyar }\end{array}$ \\
\hline $\mathrm{C}$ & Jaksa & $\begin{array}{l}\text { Jl. Jaksa Agung } \\
\text { Suprapto no. } 8, \mathrm{Kec} \text {. } \\
\text { Gresik }\end{array}$ \\
\hline $\mathrm{D}$ & Peganden & $\begin{array}{l}\text { J1. Raya Peganden, } \\
\text { Kec. Manyar }\end{array}$ \\
\hline $\mathrm{E}$ & Bungah & $\begin{array}{l}\text { Jl. Raya Bungah no. } \\
26 \text { A, Kec. Bungah }\end{array}$ \\
\hline $\mathrm{F}$ & $\begin{array}{l}\text { Dukun } \\
\text { Sembung }\end{array}$ & $\begin{array}{l}\text { J1. Raya Dukun, } \\
\text { Kec. Dukun }\end{array}$ \\
\hline G & Sekapuk & $\begin{array}{l}\text { J1. Letjen Suprapto } \\
\text { no. } 1 \text { Kec. } \\
\text { Ujungpangkah }\end{array}$ \\
\hline $\mathrm{H}$ & Dukun Sawo & $\begin{array}{l}\text { J1. Raya Petiyin, } \\
\text { RT.06/RW.02, Kec } \\
\text { Dukun }\end{array}$ \\
\hline I & Serembi & $\begin{array}{l}\text { Jl. Ruko Kembangan } \\
\text { Square no. } 1 \text {, Kec. } \\
\text { Kebomas }\end{array}$ \\
\hline $\mathrm{J}$ & Domas & $\begin{array}{l}\text { J1. Raya Domas no. } \\
\text { 38, Kec. Menganti }\end{array}$ \\
\hline $\mathrm{K}$ & Cerme & $\begin{array}{l}\text { J1. Pasar Cerme Lor } \\
\text { no. } 81\end{array}$ \\
\hline $\mathrm{L}$ & $\begin{array}{l}\text { Duduk } \\
\text { Sampeyan }\end{array}$ & $\begin{array}{l}\text { Jl. Pasar Raya } \\
\text { Duduksampeyan no. } \\
\text { 81, Kec. Duduk } \\
\text { Sampeyan }\end{array}$ \\
\hline M & Lamongan & $\begin{array}{l}\text { J1. Basuki Rahmat } \\
\text { no. 2, Kec. } \\
\text { Lamongan, Kab. } \\
\text { Lamongan }\end{array}$ \\
\hline
\end{tabular}

Sumber : GO Sumber Plastik

Jadwal pengiriman atau pendistribusi dapat dilihat pada tabel 3 dan 4. Didalam jadwal tersebut terdapat keterangan berwarna merah dan hijau sebagai tanda pengirim beserta armadanya. Adapun warna merah merupakan pengirim 1 yang menggunakan armada Tata Xenon berbahan bakar bio solar dengan konsumsi bahan bakar sebesar 10 $\mathrm{km} / \mathrm{liter}$ dan warna hijau merupakan pengirim 2 yang menggunakan armada Daihatsu
Granmax berbahan bakar pertalite dengan konsumsi bahan bakar sebesar 13 km/liter. 


\section{Penyelesaian Distribusi Reguler \\ Perusahaan}

Dalam penyelesaian distribusi reguler perusahaan pada hari senin trip 1 dapat diketahui matriks tabel 5 berikut ini :

Tabel 5. Matriks Data Jarak Tempuh Hari Senin Trip $1(\mathrm{~km})$

\begin{tabular}{|c|c|c|c|c|}
\hline Dari & A & B & C & D \\
Ke & & & & \\
\hline A & 0 & 5,6 & 8,6 & 1,4 \\
\hline B & 5,6 & 0 & 3,8 & 5,8 \\
\hline C & 8,6 & 3,4 & 0 & 8,5 \\
\hline D & 1,4 & 5,2 & 8,5 & 0 \\
\hline
\end{tabular}

Berdasarkan data yang diperoleh, maka total jarak yang diperoleh selama 1 minggu adalah sebagai berikut :

- Rute hari senin trip 1

$\mathrm{A}-\mathrm{B}-\mathrm{C}-\mathrm{D}-\mathrm{A}$

$=5,6+3,4+8,5+1,4$

$=18,9 \mathrm{~km}$

- Rute hari senin trip 2

$\mathrm{A}-\mathrm{E}-\mathrm{F}-\mathrm{G}-\mathrm{H}-\mathrm{A}$

$=17,2+11,3+7,9+15,8+44$

$=96,2 \mathrm{~km}$

- Rute hari selasa trip 1

$\mathrm{A}-\mathrm{B}-\mathrm{D}-\mathrm{A}$

$=(5,6+5,2+1,4) \times 2$

$=12,2 \mathrm{~km}$

- Rute hari selasa trip 2

$\mathrm{A}-\mathrm{I}-\mathrm{J}-\mathrm{K}-\mathrm{L}-\mathrm{M}-\mathrm{A}$

$=6,5+18+7,2+14,4+14,8+30,1$

$=91 \mathrm{~km}$

- Rute hari rabu trip 1

$\mathrm{A}-\mathrm{B}-\mathrm{C}-\mathrm{D}-\mathrm{A}$

$=5,6+3,4+8,5+1,4$

$=18,9 \mathrm{~km}$

- Rute hari rabu trip 2

$\mathrm{A}-\mathrm{E}-\mathrm{F}-\mathrm{G}-\mathrm{H}-\mathrm{A}$

$=17,2+11,3+7,9+15,8+44$

$=96,2 \mathrm{~km}$

- Rute hari kamis trip 1
$\mathrm{A}-\mathrm{B}-\mathrm{D}-\mathrm{A}$

$=(5,6+5,2+1,4) \times 2$

$=12,2 \mathrm{~km}$

- Rute hari kamis trip 2

$\mathrm{A}-\mathrm{I}-\mathrm{J}-\mathrm{K}-\mathrm{L}-\mathrm{M}-\mathrm{A}$

$=6,5+18+7,2+14,4+14,8+30,1$

$=91 \mathrm{~km}$

- Rute hari jumat trip 1

$\mathrm{A}-\mathrm{D}-\mathrm{A}$

$=1,4+1,4$

$=2,8 \mathrm{~km}$

- Rute hari jumat trip 2

$\mathrm{A}-\mathrm{B}-\mathrm{C}-\mathrm{A}$

$=5,6+3,8+8,6$

$=18 \mathrm{~km}$

- Rute hari sabtu trip 1

$\mathrm{A}-\mathrm{B}-\mathrm{I}-\mathrm{J}-\mathrm{K}-\mathrm{D}-\mathrm{A}$

$=5,6+4+18,4+7,2+16,1+1,4$

$=52,7 \mathrm{~km}$

- Rute hari sabtu trip 2

$\mathrm{A}-\mathrm{E}-\mathrm{F}-\mathrm{G}-\mathrm{H}-\mathrm{A}$

$=17,2+11,3+7,9+15,8+44$

$=96,2 \mathrm{~km}$

- Rute hari minggu

$$
\begin{aligned}
& \mathrm{A}-\mathrm{B}-\mathrm{L}-\mathrm{M}-\mathrm{D}-\mathrm{A} \\
& =5,6+14,3+14,8+29,8+1,4 \\
& =65,9 \mathrm{~km}
\end{aligned}
$$

Total jarak tempuh rute reguler perusahaan : $=(18,9 \times 2)+(96,2 \times 3)+(12,2 \times 2)+(91 \times$

2) $+2,8+18+52,7+65,9$

$=37,8+288,6+24,4+182+2,8+18+52,7$

$+65,9$

$=672,2 \mathrm{~km}$

Perusahaan memiliki 2 jenis kendaraan dengan konsumsi dan jenis bahan bakar yang berbeda. Dalam pelaksanaan dilapangan, setiap minggu pengirim 1 dan 2 dengan armadanya masing-masing akan di-rolling antara trip dekat (trip 1) dengan trip jauh (trip 2) dan pada hari minggu yang akan melaksanakan kegiatan tersebut.

Biaya bahan bakar perbulan :

- Trip 1 dan hari minggu

Tata Xenon

$=201,6 \mathrm{~km} \times 1 / 10 \mathrm{~km} / \mathrm{l}$ x Rp 5.150/1 x 2 minggu 
$=\operatorname{Rp} 207.648,-$

Daihatsu Gran Max

$=201,6 \mathrm{~km} \times 1 / 13 \mathrm{~km} / 1 \times \mathrm{Rp} 7.650 / 1 \times 2$ minggu

$=\operatorname{Rp} 237.272,4$

- $\quad$ Trip 2

Tata Xenon

$=488,6 \mathrm{~km} \times 1 / 10 \mathrm{~km} / \mathrm{l} \times \mathrm{Rp} 5150 / \mathrm{l} \times 2$ minggu

$=\operatorname{Rp} 503.258,-$

Daihatsu Gran Max

$=488,6 \mathrm{~km} \times 1 / 13 \mathrm{~km} / \mathrm{l} \times \mathrm{Rp} 7650 / \mathrm{l} \times 2$ minggu

$=\operatorname{Rp} 575.050,5$

Total biaya bahan bakar perbulan :

$=\operatorname{Rp} 207.648+\operatorname{Rp} 237.272,4+\operatorname{Rp} 503.258+$ Rp 575.050,5

$=\mathrm{Rp} 1.523 .228,9$

Penyelesaian Distribusi Metode Traveling Salesman Problem

Dalam menentukan rute distribusinya, peneliti menggunakan software WinQSB didapatkan hasil seperti pada hari senin trip 1 dibawah ini.

Gambar 2. Hasil Software Metode Branch and Bound Hari Senin Trip 1

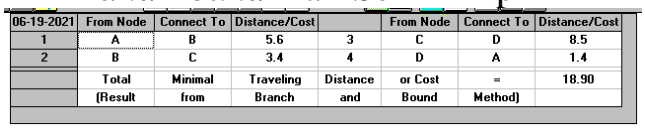

Dapat disimpulkan bahwa rute terefisien yang dapat digunakan oleh perusahaan berdasarkan software WinQSB dengan metode traveling salesman problem algoritma branch and bound adalah sebagai berikut :

Rute hari senin dan rabu trip $1 \quad$ : A

$-\mathrm{B}-\mathrm{C}-\mathrm{D}-\mathrm{A}$

Rute hari senin, rabu, dan sabtu trip 2 : A

$-\mathrm{E}-\mathrm{G}-\mathrm{H}-\mathrm{F}-\mathrm{A}$

Rute hari selasa dan kamis trip 1 : A

$-\mathrm{B}-\mathrm{D}-\mathrm{A}$

Rute hari selasa dan kamis trip $2 \quad:$ A

- I - L - M - K - J - A

Rute hari jumat trip 1

$$
\text { : A - D - A }
$$

Rute hari jumat trip 2

$$
\text { : A - C - B }
$$

Rute hari sabtu trip 1

$$
\text { : } \mathrm{A}-\mathrm{I}-\mathrm{K}-\mathrm{J}-\mathrm{B}-\mathrm{D}-\mathrm{A}
$$

Rute hari minggu

$$
\text { : A - L - M - B - D }
$$

Sehingga, dapat diketahui nilai jarak dari metode traveling saleman problem algoritma Branch and Bound dalam satu minggu adalah sebagai berikut :

$\mathrm{R} 1=$ Rute hari senin dan rabu trip 1

$=(5,6+3,4+8,5+1,4) \times 2$

$=18,9 \mathrm{~km} \times 2$

$=37,8 \mathrm{~km}$

R2 = Rute hari senin, rabu, dan sabtu trip 2

$=(17,2+15+15,8+15,7+27,4) \times 3$

$=91,1 \mathrm{~km} \times 3$

$=273,3 \mathrm{~km}$

R3 = Rute hari selasa dan kamis trip 1

$=(5,6+5,2+1,4) \times 2$

$=12,2 \mathrm{~km} \times 2$

$=24,4 \mathrm{~km}$

R4 = Rute hari selasa dan kamis trip 2

$=(6,5+14,1+14,8+12,5+14,8+$ $21,8) \times 2$

$=84,5 \mathrm{~km} \mathrm{x} 2$

$=169 \mathrm{~km}$

R5 = Rute hari jumat trip 1

$=1,4+1,4$

$=2,8 \mathrm{~km}$

R6 $=$ Rute hari jumat trip 2

$=8,6+3,4+5,6$

$=17,6 \mathrm{~km}$

R7 = Rute hari sabtu trip 1

$=6,5+12+7,2+19,8+5,2+1,4$

$=52,2 \mathrm{~km}$

$\mathrm{R} 8=$ Rute hari minggu

$=16,7+14,8+26,4+5,2+1,4$

$=64,5 \mathrm{~km}$

Total Jarak Tempuh :

$=37,8+273,3+24,4+169+2,8+17,6+$

$52,2+64,5$

$=641,6 \mathrm{~km}$

Biaya Bahan Bakar 1 bulan :

Alternatif 1

- Trip 1 dan hari minggu

T. Xenon

$=(\mathrm{R} 1+\mathrm{R} 3+\mathrm{R} 5+\mathrm{R} 7+\mathrm{R} 8) \mathrm{km} \times 1 / 10$

$\mathrm{km} /$ liter $x$ Rp 5.150,-/liter $x 2$ minggu

$=(37,8+24,4+2,8+52,2+64,5) \times 1 / 10$

x $5.150 \times 2$

$=181,7 \times 1 / 10 \times 5.150 \times 2$

$=\operatorname{Rp} 187.151,-$

D. Gran Max

$=(\mathrm{R} 1+\mathrm{R} 3+\mathrm{R} 5+\mathrm{R} 7+\mathrm{R} 8) \mathrm{km} \times 1 / 13$

$\mathrm{km} /$ liter $x$ Rp 7.650,-/liter x 2 minggu

$=181,7 \times 1 / 13 \times 7.650 \times 2$

$=\operatorname{Rp} 213.846,9$

- Trip 2 
T. Xenon

$=(\mathrm{R} 2+\mathrm{R} 4+\mathrm{R} 6) \mathrm{km} \times 1 / 10 \mathrm{~km} / \mathrm{liter} \times \mathrm{Rp}$

$5.150,-/$ liter $\mathrm{x} 2$ minggu

$=(273,3+169+17,6) \times 1 / 10 \times 5.150 \times 2$

$=459,9 \times 1 / 10 \times 5150 \times 2$

$=\operatorname{Rp} 473.697,-$

D. Gran Max

$=(\mathrm{R} 2+\mathrm{R} 4+\mathrm{R} 6) \mathrm{km} \times 1 / 13 \mathrm{~km} / \mathrm{liter} \times \mathrm{Rp}$

$7.650,-/$ liter $x 2$ minggu

$=459,9 \times 1 / 13 \times 7650 \times 2$

$=\operatorname{Rp} 541.266,9$

Total biaya bahan bakar perbulan :

$=\operatorname{Rp} 187.151+\operatorname{Rp} 213.846,9+\operatorname{Rp} 473.697+$

Rp 541.266,9

$=\operatorname{Rp} 1.415 .961,8$

Presentase penghematan biaya bahan bakar :

$=\frac{1.523 .228,9-1.415 .961,8}{1.523 .228,9} \times 100 \%$

$=7 \%$

Alternatif 2

- Trip 1

D. Gran Max

$=(\mathrm{R} 1+\mathrm{R} 3+\mathrm{R} 5+\mathrm{R} 7) \mathrm{km} \times 1 / 13 \mathrm{~km} / \mathrm{liter}$

$\mathrm{x}$ Rp 7.650,-/liter $\mathrm{x} 4$ minggu

$=(37,8+24,4+2,8+52,2) \times 1 / 13 \times 7.650$ $\mathrm{x} 4$

$=117,2 \times 1 / 13 \times 7.650 \times 4$

$=\operatorname{Rp} 275.870,8$

- Trip 2 dan hari minggu

T. Xenon

$=(\mathrm{R} 2+\mathrm{R} 4+\mathrm{R} 6+\mathrm{R} 8) \mathrm{km} \times 1 / 10 \mathrm{~km} / \mathrm{liter}$

$\mathrm{x}$ Rp 5.150,-/liter $\mathrm{x} 4$ minggu

$=(273,3+169+17,6+64,5) \times 1 / 10 \times$ $5.150 \times 4$

$=524,4 \times 1 / 10 \times 5.150 \times 4$

$=\mathrm{Rp} 1.080 .264$,-

Total biaya bahan bakar perbulan :

$\mathrm{Rp} 275.870,8+\mathrm{Rp} 1.080 .264,-=\mathrm{Rp}$ $1.356 .134,8$

Presentase penghematan biaya bahan bakar

$=\underline{1.523 .228,9-1.356 .134,8} \times 100 \%$

$$
1.523 .228,9
$$

$=11 \%$

Faktor - Faktor Distribusi di GO Sumber Plastik yang Dapat Mempengaruhi Hasil TSP

Berdasarkan hasil wawancara dengan para informan terkait faktor distribusi yang mengacu pada teori didalam penelitian Sukma (2019) dan Alfiani (2015) terdapat beberapa faktor distribusi yang mempengaruhi jarak tempuh dan biaya distribusi di GO Sumber Plastik yaitu

1. Luas Daerah

Berdasarkan hasil wawancara dengan informan kunci dan utama, perusahaan sedang mengalami perkembangan cukup signifikan yang ditandai dengan semakin bertambahnya outlet - outlet di berbagai daerah. Terbaru, terdapat penambahan outlet di Kabupaten Lamongan yang menyebabkan jangkauan pendistribusian outlet menjadi lebih besar. Hal tersebut berdampak pada jarak yang ditempuh dan biaya distribusi menjadi lebih besar. Informan Tambahan menyarankan dalam penentuan rutenya harus dilakukan secara sistematis agar dapat diperoleh biaya distribusi yang teroptimal.

2. Sarana Prasarana Internal

Informasi yang diperoleh dari informan kunci dan utama bahwa terdapat 2 jenis armada yang digunakan untuk kegiatan pendistribusian. Armada tersebut adalah Tata Xenon pick up / non box berbahan bakar bio solar dan Daihatsu Gran Max box berbahan bakar pertalite. Adanya perbedaan jenis bahan bakar menyebabkan biaya yang dikeluarkan untuk kegiatan distribusi diantara keduanya berbeda. Informan tambahan menyarankan kepada perusahaan dengan menggunakan armada Tata Xenon untuk trip jauh dan Daihatsu Gran Max untuk trip dekat dapat mengurangi beban biaya distribusi perusahaan. Karena biaya bahan bakar Tata Xenon lebih murah.

3. Faktor Cuaca

Adanya perbedaan pada fasilitas yang dimiliki kedua armada perusahaan yakni Tata Xenon tidak difasilitasi box pada bak nya dan Daihatsu Gran max memiliki fasilitas box pada bak akan menjadi masalah bagi perusahaan ketika cuaca hujan karena berpotensi dapat merusak barang yang akan didistribusikan. Berdasarkan informasi dari informan kunci, ketika hujan perusahaan akan bergantung pada armada Daihatsu Gran Max. Sebelum itu, perusahaan akan menunggu hujan selesai terlebih dahulu ketika menggunakan armada Tata Xenon. Menurutnya, hal tersebut memakan waktu dan biaya distribusi karena mengganti armada Tata Xenon dengan Daihatsu Gran 
Max. Terkait permasalahan tersebut, informan tambahan menyarankan segera memfasilitasi armada Tata Xenon dengan Box. Menurutnya, penambahan fasilitas tersebut harus menjadi prioritas utama perusahaan agar tidak menjadi kendala.

4. Faktor Kemacetan Umum

Informan kunci dan utama yang sekaligus bertindak sebagai pengirim mengatakan untuk saat kemacetan kecil tidak akan mempengaruhinya dalam menentukan rute. Namun apabila terjadi kemacetan panjang yang diakibatkan pembangunan jalan, maka informan kunci dan utama akan mencari rute alternatif agar kualitas pendistribusian dapat terjaga. Dengan mengganti rute alternatif, maka jarak tempuh dan biaya distribusi perusahaan akan mengalami kenaikan. Kualitas yang dimaksud adalah ketepatan waktu. Pendapat tersebut juga didukung oleh informan tambahan.

5. Faktor Budaya

Menurut informan kunci dan tambahan, di Gresik maupun Lamongan terdapat beberapa budaya tahunan yang menyebabkan pentutupan jalan di beberapa titik. Dengan begitu, informan kunci akan mencari alternatif lain agar pengiriman dapat tetap berjalan. Namun, jarak tempuh dan biaya distribusi akan mengalami kenaikan. Jauh sebelumnya informan kunci telah merencanakan rute alternatif karena budaya tahunan tersebut lebih mudah diprediksi titik lokasi dan waktu kejadiannya. Menurut informan tambahan, hal tersebut sudah tepat dilakukan oleh perusahaan

\section{Pembahasan}

Dari pengelolahan data diatas dapat diketahui bahwa perencanaan rute dengan metode traveling salesman problem didalam penelitian ini menghasilkan pengefisiensian biaya distribusi sebesar 7\% hingga 11\%. Sehingga, metode TSP dapat memberikan hasil yang lebih efisien dari pada hasil reguler perusahaan.. Hal ini sesuai dengan teori traveling salesman problem menurut D. B. Paillin \& Soebeko (2017) bahwa penyelesaian permasalahan distribusi menggunakan metode TSP tidak hanya dapat memberikan hasil jarak tempuh teroptimal, tetapi juga dapat mengefisiensikan biaya distribusi. Adapun algoritma yang digunakan adalah branch and bound. Menurut Al Akbar \& Sumiati (2013), Metode tersebut dapat memberikan hasil penghematan yang lebih besar dibandingkan dengan metode lainnya. Pada hasil metode TSP dalam penelitian ini, terdapat pengefisiensian jarak antara jarak reguler sebesar $672,2 \mathrm{~km}$ selama seminggu atau $2688,8 \mathrm{~km}$ selama sebulan dengan jarak menggunakan metode TSP sebesar 641,6 km selama seminggu atau $2566,4 \mathrm{~km}$ selama sebulan.

Dalam wawancara yang telah dilakukan, terdapat beberapa faktor - faktor distribusi yang mempengaruhi pengefisiensian biaya distribusi di GO Sumber Plastik berdasarkan faktor menurut Alfiani (2015) dan Sukma (2019). Adapun faktor-faktor tersebut yaitu :

1. Luas daerah

Semakin luas sebaran daerah distribusi akan mengakibatkan pendistribusian di GO Sumber Plastik menjadi semakin beragam titik tujuan. Pada kasus ini, terdapat penambahan outlet di kota Lamongan yang letaknya diluar dari wilayah Gresik menyebabkan jarak yang dilalui pada trip 2 hari selasa, kamis dan trip hari minggu terdapat biaya distribusi yang besar karena terjadi pengiriman ke outlet Lamongan. Hal ini sejalan dengan teori menurut Maharani et al., (2014) semakin luasnya sebaran distribusi dapat mempengaruhi jarak dan waktu tempuh karena dalam pengoperasiannya melibatkan jumlah armada yang dibutuhkan, biaya bahan bakar, dan rute pengiriman. Pemilihan rute perlu diperhitungkan secara sistematis agar pendistribusian yang dijalankan perusahaan lebih optimal, baik dari segi jalur yang dilalui maupun biaya yang dikenakan. Sehingga, perusahaan diharapkan menggunakan rute usulan dengan metode TSP agar biaya distribusi perusahaan dapat diminimasi.

2. Sarana prasarana internal

Pada faktor sarana-prasarana internal, perusahaan memiliki 2 jenis armada yang berbeda yakni Daihatsu Gran Max box berbahan bakar pertalite dan Tata Xenon pick up berbahan bakar bio solar. Dengan begitu, terdapat perbedaan biaya distribusi yang dikeluarkan perusahaan diantara 2 armada tersebut. Adapun perbedaan biaya 
yang dikeluarkan adalah untuk Daihatsu Gran Max menggunakan bahan bakar pertalite dengan harga $\mathrm{Rp} 7.650 /$ liter dan Tata Xenon menggunakan bahan bakar bio solar dengan harga Rp 5.150/liter. Dapat diketahui bahwa biaya yang dikeluarkan armada Tata Xenon lebih kecil daripada armada Daihatsu Gran Max. Dalam hasil dengan menggunakan metode TSP terdapat penghematan lebih besar pada alternatif 2 yaitu dengan mengganti penggunaan armada menjadi Daihatsu Gran Max dipergunakan untuk trip dekat dan Tata Xenon dipergunakan untuk trip jauh dan hari minggu. Apabila penggunaan armada dilakukan sesuai dengan jadwal reguler perusahaan maka penghematan menggunakan metode TSP sebesar 7\%. Dalam hal ini, agar hasil metode TSP dapat memperoleh hasil yang lebih optimal, perusahaan dapat menggunakan alternatif 2 dengan penghematan menjadi sebesar $11 \%$. Pada alternatif kedua, menjadikan pemilihan armada sebagai pertimbangan dalam menentukan trip jauh dengan dekat. Dengan menggunakan kendaraan berbahan bakar bio solar untuk trip jauh dan kendaraan berbahan bakar pertalite dipergunakan untuk trip dekat dapat menghasilkan pengefisiensian biaya distribusi yang lebih besar. Hal ini sesuai dengan teori Pujawan and Er (2017) bahwa menentukan mode transportasi untuk kegiatan pendistribusian merupakan salah satu fungsi dasar manajemen yang harus dilakukan dengan tepat karena setiap jenis armada memiliki keunggulan dan kekurangannya masing - masing yang berpengaruh secara langsung terhadap waktu dan pembiayaannya.

Selain itu, terdapat hal lain didalam faktor sarana prasarana internal yang dapat mempengaruhi biaya distribusi perusahan yang berkaitan dengan faktor cuaca.

3. Faktor cuaca

Ketika hujan, perusahaan mengalami kendala dalam pengiriman. Hal tersebut terjadi karena salah satu armada yakni Tata Xenon yang tidak memiliki box sehingga tidak dapat melakukan pengiriman. Perusahaan tidak ingin mengambil resiko atas kerusakan barang yang akan didistribusikan. Dengan begitu, pengiriman akan ditunda hingga hujan reda atau armada Daihatsu Gran Max yang memiliki box digunakan 2 kali ketika terdapat pengiriman yang dilaksanakan 2 trip yang berbeda dihari yang sama. Sedangkan biaya bahan bakar Daihatsu Gran Max lebih mahal daripada bahan bakar bio solar. Dengan adanya permasalahan tersebut, hasil metode TSP tidak akan bisa berjalan secara optimal. Sedangkan faktor cuaca merupakan faktor mutlak dan tidak dapat diprediksi secara tepat. Didalam teori Alfiani (2015), bahwa faktor cuaca merupakan faktor alam dan tidak dapat dicegah. Sehingga, informan tambahan menyarankan untuk segera menambah fasilitas box pada armada Tata Xenon agar aktivitas distribusi tidak terganggu. Teori dari Sukma (2019) menyatakan bahwa ketersediaan sarana prasarana khususnya pada armada yang baik dapat meningkatkan aktivitas pendistribusian.

4. Faktor kemacetan umum

Berdasarkan informasi yang diperoleh, faktor kemacetan dapat mempengaruhi pengirim menentukan rutenya apabila terjadi kemacetan panjang. Dengan mengubah rutenya maka jarak yang akan dilalui menjadi lebih panjang dan biaya distribusi akan mengalami kenaikan. Teori dari Ratnasari et al. (2013) juga menyampaikan demikian bahwa terdapat jalur alternatif dengan jarak lebih panjang yang dapat digunakan apabila jalur utama terjadi hambatan (pemblokiran jalan). Hal tersebut dilakukan untuk menjaga kualitas distribusi perusahaan. Kualitas yang dimaksud adalah waktu pengiriman. Namun apabila pengirim tidak merubah rutenya memungkinkan terjadinya kerugian pada waktu dan terjadi kenaikan pada penggunaan BBM. Didalam teori oleh Asset \& Sugiyanto (2021), terdapat biaya kerugian akibat kemacetan ditinjau dari waktu tundaan yang dialami oleh pengguna kendaraan berat maupun ringan. Dengan begitu, hasil metode TSP tidak dapat berjalan secara optimal.

5. Faktor budaya yang menyebabkan kemacetan atau penutupan jalan

Kabupaten Gresik memiliki budaya tahun yang biasa nya akan dilaksanakan ketika menjelang idul fitri. Kegiatan tersebut 
sangat beragam di berbagai daerah di Gresik. Dilansir dalam kompasiana.com beberapa tradisi unik yang biasa ditemui saat ramadhan di kota gresik yakni malam selawe dan festival pasar bandeng. Malam selawe terjadi pada hari ke-25 bulan ramadhan yang menyebabkan penutupan jalan disepanjang jalan mulai dari lampu merah kebomas hingga Sunan Giri. Festival pasar bandeng terjadi pada malam ke-27 hingga ke 29 pada bulan ramadhan yang mengakibatkan penutupan di jalan Raden Santri (utara alun-alun Gresik) hingga jalan Gubernur Suryo sepanjang kurang lebih 2 kilometer. Selaras dengan teori dari Alfiani (2015) yakni budaya atau tradisi di daerah - daerah tertentu dapat berakibat terhadap keterlambatan pengiriman karena menimbulkan penutupan (pemblokiran) akses pada suatu jalan maupun kepadatan. Hal tersebut mengakibatkan beberapa rute pengiriman mengalami penyesuaian. Dengan berubahnya rute tersebut mengakibatkan jarak yang dilalui lebih panjang dan biaya distribusi yang dikeluarkan lebih besar. Sama halnya dengan faktor kemacetan, teori yang disampaikan oleh Ratnasari et al. (2013) bahwa jalur alternatif lebih panjang dari jalur utama yang dapat dilalui ketika jalur utama sedang terjadi hambatan atau pemblokiran. Hal tersebut memungkinkan hasil metode TSP tidak berjalan secara optimal.

\section{KESIMPULAN}

Berdasarkan hasil pengolahan data dan pembahasan pada penelitian yang telah dilakukan di perusahaan GO Sumber Plastik dengan nama hukum UD. Global Indonesia Gresik yang telah teruraikan pada bab sebelumnya, maka dapat disimpulkan sebagai berikut :

1. Dengan menggunakan metode traveling salesman problem algoritma branch and bound total jarak yang dapat ditempuh oleh perusahaan hanya sebesar 641,6 $\mathrm{km} /$ minggu atau $2566,4 \mathrm{~km} / \mathrm{bulan}$ dengan pengefisiensian biaya bahan bakar yang akan dikeluarkan oleh perusahaan menjadi senilai $\mathrm{Rp}$ 1.415.961,8/bulan dengan presentase penghematan sebesar $7 \%$ apabila perusahaan menggunakan alternatif 1 dan menjadi senilai $\mathrm{Rp}$ 1.356.134,8/bulan dengan presentase penghematan sebesar $11 \%$ apabila perusahaan menggunakan altermatif 2 .

2. Dalam pelaksanaannya terdapat beberapa faktor distribusi di GO Sumber Plastik yang dapat mempengaruhi hasil metode TSP diantaranya adalah faktor luas daerah, faktor sarana prasarana internal, faktor cuaca, faktor kemacetan umum, dan faktor budaya yang menyebabkan pemblokiran atau kepadatan pada suatu tempat.

\section{REFERENSI}

Akbar, Fahmi Fuadi Al, and Sumiati. 2013. "Penentuan Rute Distribusi Teh Botol Menggunakan Metode." Journal of Industrial Engineering and Management 9 (3): 121-31.

Alfiani, Alifia. 2015. "Tinjauan Keterlambatan Pengiriman Parts Serta Klaim Pada Pt United Tractors." Logistik D III Transportasi UNJ VIII (2): 37-40.

Asset, M. Ameer, and Sugiyanto Sugiyanto. 2021. "Analisa Biaya Kerugian Karena Mengalami Kondisi Kemacetan Akibat Perbaikan Jalan Ditinjau Dari Waktu Tunda Perjalanan Dan Kenaikan Bahan Bakar Minyak (Bbm) Kendaraan." Rang Teknik Journal 4 (1): 143-63. https://doi.org/10.31869/rtj.v4i1.2268.

Auliasari, Karina, Mariza Kertaningtyas, and Diah Wilis Lestarining Basuki. 2018. "Optimalisasi Rute Distribusi Produk Menggunakan Metode Traveling Salesman Problem." Jurnal Sains, Teknologi Dan Industri 16 (1): 15. https://doi.org/10.24014/sitekin.v16i1.6 109.

CNN Indonesia. 2020. "Jokowi Keluhkan Biaya Logistik Antar Daerah RI Masih Mahal." Www.Cnnindonesia.Com. 2020.

Effendi, Ahmad, Yustina Ngatilah, and Iriani. 2016. "Penentuan Rute Optimal Distribusi Produk Dengan Metode Algoritma Ant Colony Optimization Di Pt . Romindo Primavetcom." Jurnal Teknik Industri 5 (2): 26-34.

Fitri, Sri June, Nurul Huda, and Evi Susanti 
Tasri. 2016. "Optimalisasi Sistem Transportasi Produk Olahan Kacang Pt . Garuda Food Di Kota Solok Dengan Pendekatan Model Quantitative System Business ( Studi Kasus PT. Garuda Food )." Jurnal Fakultas Ekonomi 8 (3). https://ejournal.unsri.ac.id/index.php/m ining/article/view/3814.

Maharani, Ni Luh, Rusidiyanto, and Budi Santoso. 2014. "Minimasi Biaya Pendistribusian Pupuk Dengan Metode Travelling Salesman Problem (TSP) Studi Kasus PT. Bunga Tani Lamongan.”

https://hsgm.saglik.gov.tr/depo/birimler /saglikli-beslenme-hareketli-hayat$\mathrm{db} /$ Yayinlar/kitaplar/digerkitaplar/TBSA-Beslenme-Yayini.pdf.

Moriza, Dicky, Hari Adiyanto, and Yodi Nurdiansyah. $2016 . \quad$ "Rute Pendistribusian Air Mineral Dalam Kemasan Menggunakan Metode Nearest Neighbour Dan Branch and Bound Di PT Agronesia BMC." Reka Integra Itenas 4 (2): 195-205. https://ejurnal.itenas.ac.id/index.php/re kaintegra/article/view/1101.

Mursy, Abdul Azis Lalu, Hibban Kholiq, Diah Ayu Saptyaningtyas, Rina Juliana, Mira Sulisdiana, and Mamika Ujianita Romdhini. 2019. "Menentukan Rute Terpendek Pendistribusian Bahan Bangunan Oleh PT. Sadar Jaya Manunggal Mataram Menggunakan Algoritma Branch and Bound." EIGEN MATHEMATICS JOURNAL 1 (1): 54. https://doi.org/10.29303/emj.v1i1.24.

Paillin, D. B., and Filinda Sosebeko. 2017. "Penentuan Rute Optimal Distribusi Produk Nestle Dengan Metode Traveling Salesman Problem (TSP) (Studi Kasus : PT. Paris Jaya Mandiri)." ARIKA 11 (1): 35-44. https://doi.org/10.30598/arika.2017.11. 1.35 .

Paillin, Daniel B, and Johan M Tupan. 2018. "Pemecahan Traveling Salesman Problem Menggunakan Teknik Branch and Bound Dan Cheapest Insertion Heuristic (Studi Kasus: PT. Paris Jaya Mandiri - Ambon)." Seminar Dan Konferensi Nasional IDEC, no. 2014: 7 8.

Pramesti, Cory. 2019. "Beberapa Tradisi
Unik Yang Bisa Kalian Temui Saat Menikmati Bulan Ramadhan Di Kota Gresik.” Kompasiana.Com. 2019. https://thr.kompasiana.com/coryprames sti/5cd542003ba7f77488044133/bebera pa-tradisi-unik-yang-biasa-ditemuisaat-ramadhan-di-kota-gresik?page=all. Pujawan, I Nyoman, and Mahendrawathi Er. 2017. Supply Chain Management. Edited by Maya. Edisi 3. Yogyakarta: ANDI.

Ratnasari, Asti, Farida Ardiani, and Feny Nurvita A. 2013. "Penentuan Jarak Terpendek Dan Jarak Terpendek Alternatif Menggunakan Algoritma Dijkstra Serta Estimasi Waktu Tempuh." Semantik 20133 (1): 29-34.

Siraj, Muh. Mufid. 2020. "Penentuan Biaya Transportasi Minimum Pada Pemilihan Rute Pengiriman Menggunakan Metode Clark And Wright Saving Heuristic." Jurnal Ilmiah Matematika 8 (1): 7-16.

Sukma, Rizka Diah Melati. 2019. "Prosedur Pendistribusian Barang Milik Ajinomoto Sales Indonesia Pada PT. Ajinomoto Indonesia." 53 (9): 1689-99. Suryanto, Mikael Hang. 2016. Sistem Operasional Manajemen Distribusi. Edited by Trian Lesmana. Jakarta: PT Grasindo. https://books.google.co.id. 